\title{
IMPLEMENTASI TEKNIK VOKAL NASAL PADA \\ PADUAN SUARA MAHASISWA SOLFEGGIO \\ CHOIR UNIVERSITAS NEGERI MEDAN
}

\author{
SISKA MAGDALENA SIREGAR \\ Prodi PendidikanMusik
}

\begin{abstract}
Siska Magdalena Siregar. NIM 2133340042. Implementasi Teknik Vokal Nasal Pada Paduan Suara Mahasiswa Solfeggio Choir Universitas Negeri Medan. Fakultas Bahasa dan Seni. Universitas Negeri Medan 2018.

Penelitian ini bertujuan untuk mengetahui proses implementasi teknik vokal nasal pada Paduan Suara Mahasiswa Solfeggio Choir Universitas Negeri Medan. Tujuan penelitian ini adalah untuk mengetahui karakteristik teknik vokal Nasal pada Paduan Suara Mahasiswa Solfeggio Choir Universitas Negeri Medan, untuk mengetahui fungsi implementasi teknik vokal Nasal pada Paduan Suara Mahasiswa Solfeggio Choir Universitas Negeri Medan, untuk mengetahui hasil yang diperoleh setelah mengimplementasikan teknik vokal Nasal pada Paduan Suara Mahasiswa Solfeggio Choir Universitas Negeri Medan.
\end{abstract}

Teori yang digunakan adalah teori implementasi, teknik vokal, teknik vokal nasal, paduan suara. Implementasi adalah perluasan aktivitas yang saling menyesuaikan. Teknik vokal adalah suatu cara memproduksi suara yang baik dan benar, sehingga suara yang keluar terdengar jelas, indah, merdu, dan nyaring. Teknik vokal nasal adalah vokal yang diartikulasikan dengan udara yang keluar dari hidung yang menghasilkan bunyi suara yang sengau. Paduan suara atau koor merupakan istilah yang merujuk kepada ensambel musik yang terdiri atas penyanyi-penyanyi maupun musik yang dibawakan oleh ensambel tersebut.

Metode dalam penelitian ini menggunakan metode deskriptif kualitatif. Sampel dalam penelitian ini adalah anggota Paduan Suara Mahasiswa Solfeggio Choir Universitas Negeri Medan, partitur dan audio visual dari lagu Tandai Ma $A u$. Pengumpulan data ini dilakukan dengan metode observasi atau pengamatan, wawancara, dokumentasi dan studi kepustakaan. Penelitian ini di ambil di Sekretariat Paduan Suara Mahasiswa Solfeggio Choir Universitas Negeri Medan, dan penelitian ini dilaksanakan dari bulan Oktober 2017.

Hasil penelitian ini menunjukkan bahwa implementasi teknik vokal nasal pada Paduan Suara Mahasiswa Solfeggio Choir Universitas Negeri Medan harus diawali dengan pemanasan, olah vokal serta berlatih pernafasan terlebih dahulu karena hal tersebut sangat penting dan berpengaruh pada saat bernyanyi agar tidak terjadi cedera pada pita suara. setelah melakukan pemanasan lalu terapkanlah teknik nasal tersebut dengan menyanyikan sebuah lagu. Contoh lagu yang diambil adalah lagu 
Tandai $M a A u$. Hasil yang diperoleh pada saat bernyanyi menggunakan teknik nasal tersebut adalah suara yang dikeluarkan terdengar lebih jernih dan liris berbeda ketika bernyanyi dengan teknik biasa.

Kata Kunci: Implementasi, Teknik Vokal Nasal.

\section{PENDAHULUAN}

\section{A. Latar Belakang Masalah}

Musik merupakan keindahan suara yang dapat didengar. Sumber suara tersebut memiliki dua macam asalnya yaitu yang dihasilkan oleh alat-alat musik dan yang dihasilkan oleh manusia. Suara yang dihasilkan oleh alat-alat musik disebut instrument musik dan suara yang dihasilkan oleh manusia disebut vokal.

Paduan suara merupakan sajian musik vokal dengan memadukan berbagai jenis warna suara (timbre) menjadi satu kesatuan yang utuh dan dapat mengungkapkan jiwa lagu yang dinyanyikan.. Bernyanyi di dalam paduan suara juga membutuhkan choral voice yang baik. Cara mendapatkan choral voice yang baik adalah dengan menerapkan teknik vokal dasar yaitu sikap badan,
Musik vokal merupakan kegiatan bermusik yang menggunakan suara manusia sebagai media utamanya. Musik vokal bisa dimainkan oleh seorang penyanyi atau sekelompok orang. jika dinyanyikan perorangan disebut solo, dan jika dinyanyikan oleh sekelompok orang disebut suara bersama. Dan suara bersama ini apabila dinyanyikan dengan harmoni dan berbagai warna suara seperti sopran, alto, tenor dan bas disebut paduan suara atau choir (koor).

pernapasan, pengolahan suara, artikulasi, dan frasering.

Setelah menggunakan teknik dasar tersebut, lalu menerapkan teknik vokal yaitu teknik vokal nasal. Paduan suara di kota Medan yang menerapkan teknik nasal adalah Paduan Suara Mahasiswa Solfeggio Choir Universitas Negeri Medan. Paduan suara ini menggunakan teknik nasal karena ketika bernyanyi menggunakan teknik nasal suara yang 
dihasilkan atau bunyi yang dihasilkan terdengar lebih liris, tajam dan sengau serta dibantu dengan pernapasan diafragma fungsi dari penggunaan teknik nasal juga membantu para penyanyi lebih fokus lagi dalam bernyanyi sehingga pitch control nya menjadi lebih baik.

Kemampuan Solfeggio Choir dalam menyanyikan lagu-lagu paduan suara dengan menggunakan teknik nasal inilah yang menjadi motivasi dan ketertarikan untuk meneliti penerapan teknik vokal nasal tersebut. Maka judul yang akan diangkat menjadi sebuah penelitian adalah "Implementasi Teknik Vokal Nasal Pada Paduan Suara Mahasiswa Solfeggio Choir Universitas Negeri Medan".

\section{B. Tujuan Penelitian}

1. Untuk mengetahui karakteristik teknik vokal nasal yang diimplementasikan pada Paduan Suara Mahasiswa Solfeggio Choir Universitas Negeri Medan.

2. Untuk mengetahui implementasi teknik vokal nasal pada Paduan Suara
Mahasiswa Solfeggio Choir Universitas Negeri Medan.

3. Untuk mengetahui kemampuan yang diperoleh setelah mengimplementasikan teknik vokal nasal pada Paduan Suara Mahasiswa Solfeggio Choir Universitas Negeri Medan.

\section{LANDASAN TEORI}

Landasan teoritis adalah deskriptif dari hasil suatu studi kepustakaan yang berhubungan (relevan) serta mendukung pokok permasalahan yang hendak diteliti, sehingga landasan teoritis ini diharapkan mampu menjadi landasan atau acuan maupun pedoman dalam penyelesaian masalah-masalah yang timbul dalam penelitian ini.

A. Implementasi

Menurut Browne dan Widalvsky (dalam Nurdin dan Usman, 2004:70) yang mengatakan bahwa "Implementasi adalah aktivitas yang saling menyesuaikan". Adapun Schubert (Dalam Nurdin dan Usman, 2002 :70) mengemukakan bahwa"Penerapan adalah sistem rekayasa".) Berdasarkan beberapa pendapat para ahli mengenai implementasi, maka penulis 
berkesimpulan bahwa implementasi merupakan suatu proses pemberian suatu kegiatan kepada kelompok atau individu dengan cara yang baik dan memang layak untuk disampaikan dengan maksud mencapai tujuan sebuah kegiatan dengan baik.

\section{B. Teknik Vokal}

Menurut N.Simanungkalit (2008:44) yang mengatakan bahwa teknik vokal merupakan hal yang penting, namun tidak berarti mengabaikan unsure lain, seperti ekspresi. Vokal paduan suara dalam pelajaran ilmu paduan suara disebut choral voice dimana choral voice berbeda dengan suara solo.

Teknik vokal adalah teknikteknik yang digunakan oleh penyanyi dalam membawakan sebuah karya musik vokal. tujuan penggunaan teknik vokal adalah agar diperolehnya produksi suara yang baik sebagai media penyampaian gagasan musik sehingga dapat menghasilkan sajian vokal yang dapat menyampaikan ideide musik secara tepat dan indah. Terdapat beberapa unsur-unsur yang harus diperhatikan dalam menerapkan cara atau metode dasar agar produksi suara yang dikeluarkan ketika bernyanyi terdengar lebih jelas, merdu dan nyaring yaitu sikap badan, pembentukan suara dan pengolahan suara, pernapasan, pernapasan, pengucapan, resonansi, frasering, dan penjiwaan.

Berdasarkan

beberapa

pendapat para ahli mengenai teknik vokal maka penulis berkesimpulan bahwa teknik vokal adalah suatu cara memproduksisuara yang baik dan benar, sehingga suara yang keluar terdengar jelas, indah, merdu dan nyaring.

C. Teknik Vokal Nasal

Vokal adalah bunyi hurufhuruf yang terdapat dalam jajaran alfabet yang pada dasarnya berkisar pada huruf a, i, u, e dan o. Vokal nasal adalah vokal yang diartikulasikan dengan udara yang keluar dari hidung yang menghasilkan bunyi suara yang sengau. Jika udara keluar melalui rongga hidung, dengan cara menurunkan langit-langit lunak beserta ujung anak tekaknya maka bunyi tersebut disebut bunyi nasal atau sengau. Pernapasan hidung atau vokal nasal berfungsi membantu para 
penyanyi menghasilkan nada tinggi dengan cara yang benar. Fungsi dari penggunaan teknik vokal nasal juga membantu para penyanyi mampu berkonsentrasi penuh pada saat memulai bernyanyi atau melakukan aba-aba awal dengan baik dan rapi. Vokal nasal banyak terdapat dalam bahasa Perancis dan konsonannya yaitu $m$ dan $n$. Kedua bunyi vokal tersebut seperti $m$ dan $n$ tidak pernah dibunyikan pada akhir sebuah nasal. Pada saat mengakhiri bunyi, jaga sedapat mungkin agar lidah tidak bergerak naik menuju langit-langit mulut. Produksi suara yang dihasilkan melalui teknik nasal ini sedikit lebih tajam dan liris dibandingkan dengan teknik vokal lainnya.

\section{Paduan Suara}

Paduan suara atau koor merupakan istilah yang merujuk kepada ensambel musik yang terdiri atas penyanyi maupun musik yang dibawakan oleh ensambel tersebut. Umumnya suatu kelompok paduan suara membawakan musik paduan suara yang terdiri atas beberapa bagian suara. Menurut Yudha Pramayuda (2010:63) terdapat beberapa jenis-jenis paduan suara yaitu Paduan suara Unisono, Paduan Suara 2 suara sejenis, Paduan Suara 3 suara sejenis, Paduan Suara 3 suara campuran, Paduan Suara 3 sejenis dan Paduan Suara 4 suara campuran. Dalam praktek paduan suara membutuhkan beberapa kemampuan yang mencakup kemampuan membaca notasi (partitur), teknik pernapasan, teknik pembentukan suara, artikulasi serta kemampuan membaca tanda-tana dinamika musik.

\section{E. Karakteristik}

Karakteristik berasal dari kata karakter yang berarti unsur psikososial yang dikaitkan dengan pendidikan dan konteks lingkungan. Menurut Nanda (2013) bahwa "Karakteristik adalah mengacu kepada karakter dan gaya hidup seseorang serta nilai-nilai yang berkembang secara teratur sehingga menjadi lebih konsisten dan mudah diperhatikan.

Pada implementasi teknik vokal di Solfeggio Choir, sebelum memulai proses implementasi anggota harus mengetahui dahulu apa karakteristik yang terdapat pada teknik nasal 
supaya pada proses implementasi anggota Solfeggio Choir lebih mudah mencapai hasil yang baik.

F. Kemampuan

Kemampuan merupakan hal yang paling penting dalam proses pembelajaran musik karena sebagai pendukung terbentuknya prestasi dalam pembelajaran musik. Menurut Robbin (2007:57) bahwa "Kemampuan berarti kapasitas seorang individu untuk melakukan beragam tugas dalam suatu pekerjaan atau lebih lengkapnya Robbin mengatakan bahwa kemampuan adalah sebuah penilaian terkini atas apa yang dapat dilakukan seseorang.

Berdasarkan pengertian diatas dapat disimpulkan bahwa kemampuan adalah kecakapan atau potensi seseorang untuk menguasai keahlian dalam melakukan atau mengerjakan tugas dalam suatu pekerjaan atau suatu penilaian atas tindakan seseorang. Hasil dalam implementasi teknik vokal nasal ini diharapkan anggota Solfeggio Choir mampu menyanyikan sebuah lagu dengan baik, bernyanyi dengan cara yang baik dan benar.
METODOLOGI PENELITIAN

\section{A. Lokasi dan Waktu Penelitian}

\section{Lokasi Penelitian}

Sesuai dengan judul penelitian "Implementasi Teknik Vokal Nasal Pada Paduan Suara Mahasiswa Solfeggio Choir Universitas Negeri Medan”, Maka penelitian ini dilakukan di Sekretariat Paduan Suara Mahasiswa Solfeggio Choir Universitas Negeri Medan.

\section{Waktu Penelitian}

Waktu penelitian dan proses Penelitian dilaksanakan pada bulan Oktober-Desember 2017.

\section{B. Populasi dan Sampel}

\section{Populasi}

Populasi dalam penelitian ini adalah anggota PSM Solfeggio Choir UNIMED yang berjumlah 35 orang.

\section{Sampel}

Sampel dalam penelitian ini adalah anggota PSM Solfeggio Choir UNIMED yang berjumlah 9 orang dan 1 orang pelatih sekaligus konduktor Solfeggio Choir.

\section{Teknik Pengumpulan Data}

\section{Wawancara}

Dengan adanya metode wawancara, penulis akan bertanya kepada informan tentang 
implementasi teknik vokal nasal pada Paduan Suara Mahasiswa Solfeggio Choir Universitas Negeri Medan dan beberapa pertanyaan lainnya mengenai teknik vokal nasal tersebut.

\section{Dokumentasi}

Sesuai dengan pendapat tersebut, maka penulis menggunakan metode dokumentasi yaitu dengan mendokumentasikan pertemuan wawancara dengan informan yaitu Halim Suwito Pakpahan badan pengurus harian Solfeggio Choir, Aditia Kartika salah satu anggota Solfeggio Choir, Zul Hazmi Harahap salah satu anggota Solfeggio Choir, Rocky Sihotang, S.Pd pelatih sekaligus konduktor di Paduan Suara Mahasiswa Solfeggio Choir Universitas Negeri Medan.

\section{Observasi}

Observasi yang dilakukan oleh penulis adalah mengamati setiap proses latihan yang berlangsung di Paduan Suara Mahasiswa Solfeggio Choir Universitas Negeri Medan untuk mengetahui bagaimana implementasi teknik vokal nasal pada Paduan Suara Mahasiswa Solfeggio Choir Universitas Negeri Medan.

\section{Studi Kepustakaan}

Penulis mencari dan membaca beberapa literatur seperti buku dan artikeln yang relevan dengan pokok yang akan dibahas. Dengan adanya sumber-sumber pustaka tersebut maka dapat diperoleh banyak informasi yang membantu penulis dalam mengerjakan penelitian ini.

\section{Teknik Analisis Data}

Berdasarkan pendapat, maka tahapan analisis data dalam penelitian ini akan diupayakan untuk memperdalam atau menginterpretasi data secara spesifik dalam rangka mendeskripsikan tujuan penelitian.

\section{ISI}

\section{A. Paduan Suara Mahasiswa Solfeggio Choir Universitas Negeri Medan.}

Paduan Suara Mahasiswa Solfeggio Choir Universitas Negeri Medan berdiri sejak tahun 1991 atas dasar adanya keinginan untuk bernyanyi bersama antara mahasiswamahasiswi yang mengenyam pendidikan di UNIMED. Solfeggio Choir sendiri memiliki visi dan misi untuk melayani serta menuju ke tahap profesional, dan juga tidak bergerak dibidang rohani saja melainkan di segala aspek sosial masyarakat. Pada 
saat ini Solfeggio Choir memiliki anggota sebanyak 35 orang. Solfeggio Choir dibina oleh Ibu Dra. Theodora Sinaga, M.Pd dan dilatih oleh Rocky Sihotang, $\quad$ S.Pd. Selama keberadaannya Solfeggio Choir juga telah berhasil mengukir prestasi serta mengikuti beberapa festival yang diadakan didalam maupun diluar kota Medan, serta tingkat nasional maupun internasional.

\section{B. Karakteristik Teknik Vokal Nasal Pada Paduan Suara Mahasiswa Solfeggio Choir Universitas Negeri Medan}

Teknik vokal nasal adalah vokal yang diartikulasikan dengan udara yang keluar dari hidung yang menghasilkan bunyi suara yang sengau. Beberapa karakteristik teknik vokal nasal adalah bentuk vokal yang dihasilkan jauh lebih baik dan pengucapannya lebih jelas karena pada saat bernyanyi menggunakan teknik nasal dibantu dengan pernafasan diaphragma, Suara yang dihasilkan lebih nyaring dan tajam karena pada saat bernyanyi suara yang dikeluarkan dinaikkan melalui hidung menuju ubun-ubun sehingga suara yang terdengar lebih bersih dan jernih dan suara yang dihasilkan terdengar seperti suara seseorang yang sedang flu atau sengau karena menggunakan teknik nasal atau suara yang dikeluarkan melalui hidung.

Karakteristik dari tiap jenis suara pada paduan suara ketika menggunakan teknik nasal pada saat bernyanyi memiliki hasil yang sama. Yang membedakan adalah produksi suara pria dan wanita.

\section{Implementasi Teknik Vokal Nasal Pada Paduan Suara Mahasiswa Solfeggio Choir} Universitas Negeri Medan.

Berdasarkan hasil penelitian di sekretariat Paduan Suara Mahasiswa Solfeggio Choir Universitas Negeri Medan, terdapat beberapa proses latihan yang dilakukan oleh pelatih kepada anggota Solfeggio Choir. Sebelum memulai proses latihan, anggota Solfeggio Choir terlebih dahulu melakukan kegiatan rutin setiap hari yaitu kebersihan atau biasa disebut gotong royong dengan tujuan mempererat kebersamaan antar sesama anggota Solfeggio Choir dan menjaga kebersihan lingkungan 
sekretariat Solfeggio Choir dan kampus Universitas Negeri Medan. Kegiatan ini dilakukan sebelum dan sesudah proses latihan berlangsung. Sebelum proses latihan dimulai, salah satu anggota Solfeggio Choir membawakan doa pembuka, begitu juga pada saat selesai latihan ditutup kembali dengan doa. Begitu seterusnya kegiatan rutin yang dilakukan sebelum dan sesudah proses latihan.

Solfeggio Choir belum menggunakan teknik vokal dengan sempurna. Sebelum menggunakan teknik nasal, Solfeggio Choir dulunya hanya menggunakan teknik resonansi pada saat bernyanyi dimana suara yang dihasilkan bagus tetapi belum mencapai hasil yang maksimal, karena belum mampu mencapai tingkat keharmonisan yang baik. Menggunakan teknik resonansi juga belum mampu menyamakan timbre suara anggota Solfeggio Choir, oleh karena itu Solfeggio Choir memilih untuk mengimplementasikan teknik nasal karena pada saat menerapkan teknik nasal otomatis teknik resonansi juga akan digunakan.
Proses implementasi teknik vokal dilakukan di Solfeggio Choir dimana Solfeggio Choir adalah paduan suara yang memiliki anggota yang berasal dari berbagai fakultas dan jurusan di Universitas Negeri Medan. Namun secara umum, anggota Solfeggio Choir didominasi oleh mahasiswa dari jurusan Sendratasik tepatnya pada program pendidikan seni musik. Hal ini dikarenakan mahasiswa yang berasal dari program pendidikan seni musik lebih tertarik kepada dunia paduan suara daripada mahasiswa yang berasal dari fakultas atau jurusan lain. Namun bukan berarti mahasiswa dari fakultas lain tidak tertarik, mereka juga tertarik dan mau belajar bernyanyi di Solfeggio Choir.

D. Kemampuan Yang Diperoleh Paduan Suara Mahasiswa Solfeggio Choir UNIMED Setelah Menerapkan Teknik Vokal Nasal.

Berdasarkan wawancara yang dilakukan dengan Rocky Sihotang, S.Pd (Wawancara pada tanggal 11 November 2017) bahwa implementasi teknik vokal nasal akan berhasil 
apabila berhasil juga dalam menyanyikan sebuah lagu dengan baik. Menurut Aditia Kartika yaitu salah satu anggota Solfeggio Choir yang sudah menerapkan teknik nasal tersebut, hasil yang sudah diperoleh adalah ketika memakai teknik nasal suara yang dihasilkan atau bunyi yang dikeluarkan terdengar seperti dengungan, berbeda dengan ketika bernyanyi menggunakan teknik biasa. Begitu juga dengan anggota Solfeggio Choir yang bernama Zul Hazmi Harahap mengatakan bahwa hasil yang diperoleh setelah menerapkan teknik nasal adalah lebih gampang mencapai nada-nada tinggi maupun nada-nada rendah dalam sebuah lagu.

\section{PENUTUP}

Berdasarkan hasil penelitian yang telah dilakukan, maka penulis membuat beberapa kesimpulan diantaranya :

1. Paduan Suara

Mahasiswa Solfeggio Choir

Universitas Negeri Medan terbentuk pada tahun 1991 yang didalamnya beranggotakan mahasiswa-mahasiswi UNIMED yang memiliki keinginan untuk bernyanyi serta mengukir prestasi melalui talenta yang dimiliki.
Solfeggio Choir dibina oleh Ibu Dra.Theodora Sinaga, M.Pd dan dilatih oleh Rocky Sihotang, S.Pd yang saat ini masih berstatus mahasiswa UNIMED. Solfeggio Choir sendiri memiliki visi dan misi untuk melayani serta menuju ke tahap profesional. Hal ini ditunjukkan Solfeggio Choir sendiri pada prestasi yang telah dicapai tiap tahun dalam event-event paduan suara yang diikuti mereka. Bukan hanya kegiatan rutin melainkan dengan kegiatan insidental atau tidak terjadwal. Dengan motto "Untuk Tuhan, Bangsa, dan Almamater" mereka mengukir prestasi dengan bernyanyi dengan tulus dan profesional.

2. Berdasarkan data yang diperoleh, karakteristik teknik nasal yang diimplementasikan oleh Paduan Suara Mahasiswa Solfeggio Choir UNIMED adalah bentuk vokal yang dihasilkan jauh lebih baik dan pengucapannya lebih jelas karena pada saat bernyanyi menggunakan teknik nasal dibantu dengan pernafasan diafragma, suara yang dihasilkan lebih nyaring dan tajam karena pada saat bernyanyi suara yang dikeluarkan dinaikkan melalui 
hidung menuju ubun-ubun sehingga suara yang terdengar lebih bersih dan jernih, suara yang dihasilkan terdengar seperti suara seseorang yang sedang flu atau sengau karena menggunakan teknik nasal atau suara yang dikeluarkan melalui hidung.

3. Proses implementasi teknik vokal nasal pada Paduan Suara Mahasiswa Solfeggio Choir UNIMED yaitu dimulai dari pemanasan terlebih dahulu sebelum bernyanyi karena pemanasan dalam bernyanyi sangat penting agar pada saat bernyanyi suara kita sudah fit dan tidak terjadi kesalahan atau cidera pada pita suara. Pada saat bernyanyi atau menyanyikan sebuah lagu, terapkanlah teknik nasal tersebut dengan menaikkan suara ke atas hidung dengan bantuan ubun-ubun agar suara yang dikeluarkan naik ke atas dan tidak keluar secara langsung ke depan mulut, bila diperlukan naikkanlah alis agar suara yang dihasilkan lebih jernih. Pada saat bernyanyi gunakanlah pernapasan diafragma agar suara yang dihasilkan bertenaga atau ber power (bertenaga). Pada proses implementasi teknik nasal di Solfeggio Choir, kesulitan- kesulitan yang ditemukan pada saat latihan adalah ketika salah satu anggota belum mampu mempraktekkan teknik nasal tersebut dengan baik, maka pelatih tidak akan melanjutkan proses latihan berikutnya kepada anggota lain, dalam artian bahwa semua harus serentak belajar bersama-sama dari awal dan harus mampu mempraktekkan bersamasama dengan baik pula. Hal ini dikarenakan tidak semua anggota memiliki latar belakang yang sama, ada yang berasal dari program pendidikan musik, ada pula yang sama sekali tidak mengerti musik. Daya tangkap yang dimiliki setiap anggota juga berbeda-beda, baik sesame mahasiswa yang mengerti musik, ataupun sebaliknya yang tidak mengerti musik. Bahkan ada pula yang sama sekali tidak mengerti musik tetapi memiliki daya tangkap yang cepat dibandingkan mahasiswa yang mengerti musik.

4. Kemampuan yang diperoleh setelah menerapkan teknik vokal nasal tersebut adalah suara yang dihasilkan lebih jernih daripada menggunakan teknik biasa. Pada saat bernyanyi, penyanyi lebih mudah 
menjangkau nada-nada tinggi dengan baik dan tidak ada paksaan. Dapat dilihat dari hasil penelitian ini, pada lagu Tandai $M a A u$ suara mereka terdengar sangat liris jika kita lihat dari suara wanita yang mengambil nada tinggi maupun suara pria yang mengambil nada rendah. Pada pencapaian tersebut, mereka menerapkan teknik nasal dengan baik.

\section{DAFTAR PUSTAKA}

Ehmann, Wilhem. 1968. Choral Directing. United States of America: Augsburg Publishing House.

Egisthi, Vonny Afryona, dkk. 2016. Aplikasi Latih Vokal Dengan Menggunakan Metode Harmonic Product Spectrum (HPS) Dan Boyer Moore Bersasis Android. Bengkulu: Jurnal. Fakultas Teknik, Program Studi Teknik Informatika, Universitas Bengkulu.

Hadeli. 2006. Metode Penelitian Kependidikan. Ciputat: Quantum Teaching

Http://belajarilmubahasa.blogspot.co. d/2014/01/klasifikasi-bunyi-bahasanasal-dan-oral.html?m=1
Http://el-

kawaqi.blogspot.co.id/2012/12/penge

rtian-implementasi-menurut-

para.html?m=1

Http://andimusicgitar.blogspot.co.id/2 012/02/defenisi-vocal.html?m=1

Karthika, Guido Denta Christian, dkk. 2013 . Metode Latihan Paduan Suara Universitas Airlangga Oleh Yosafat Rannu Leppong. Surabaya: Jurnal. Sendratasik FBS Universitas Negeri Surabaya

Listya, Agastya Rama. 2007. A-Z Direksi Paduan Suara. Jakarta: YAMUGER

Moleong, Lexy. 2008. Metodologi Penelitian Kualitatif. Bandung: PT. Remaja Rosda Karya

MY, Rudy 2008. Panduan Olah Vokal. Yogyakarta: Media Pressindo

Nazir. 2011. Metode Penelitian. Bogor: Ghalia Indonesia

Nurdin dan Usman. 2012. Teori Penerapan.

Nurmalinda. 2013. Pembelajaran Teknik Vokal Pada Paduan Suara 
Lagu Hymne Guru Di SMPN Toar Kecamatan Gunung Toar Kabupaten Kuantan Singingi Provinsi Riau. Riau: Jurnal. FKIP Universitas Islam Riau.

Pramayuda, Yudha. 2010. Buku Pintar Olah Vokal. Yogyakarta: BUKUBIRU

Sihotang, Reyapruma Rocky. 2014. Tinjauan Penerapan Teknik Vokal dan Komposisi Aransemen Lagu pada Grup Nasyid Maidany. Medan: Skripsi Fakultas Bahasa dan Seni Universitas Negeri Medan

Simanungkalit,N. 2008. Teknik Vokal Paduan Suara. Jakarta: PT. Gramedia Pustaka Utama

Sugiyono. 2012. Metode Penelitian Kuantitatif, Kualitatif, Dan $R \& D$. Bandung: Alfabeta

Suharsimi, Arikunto. 2006. Prosedur Penelitian Suatu Pendekatan Praktik. Jakarta: PT. RINEKA CIPTA

Tohirin. 2012. Metode Penelitian Kualitatif Dalam Pendidikan dan Bimbingan Konseling. Jakarta: PT. Raja Grafindo Persada.
Zendrato, Pranata, P, Narita. 2015. Teknik Vokal dan Makna Lagu Maena Dalam Acara Pernikahan Adat Nias di Desa Hilimbosi Kecamatan Sitolu Ori Kabupaten Nias Utara. Medan: Skripsi Fakultas Bahasa dan Seni Universitas Negeri Medan.

Sudibyo, Priyatmo. 2006. Teknik Dasar Bermain Keyboard. Naga Swadaya

Sugiyono. 2016. Metode Penelitian,kuantitatif, Kualitatif dan $R \& D$. Bandung : Alfabeta.

Suharyanto, A. 2017.Sejarah Pendidikan Musik Klasik Non Formal di Kota Medan.Gondang.

Suharyanto, A. 2010.Makna Belajar Musik Klasik Dan Tari Ballet Bagi Keluarga Etnis Cina di Medan. Tdv Medan: Unimed.

Sukardi. 2013. Metode Penelitian Pendidikan. Jakarta : Bumi Aksara.Suryana, Dayat. 2012. Terapi Musik.

Tambajong, Japi. 1992. Ensiklopedia Musik Jilid 1. Jakarta : PT. Cpta Adi Pustaka 
Usman K, 1979. Komponis-komposis

Terkemuka.PT Aries Lima.

Widhayatama, Sila. 2012. Sejarah

Musik dan Apresiasi Seni.PT Balai

Pustaka

http://id.m.wikipedia

$\underline{\text { www.educenter.id }}$ 